\title{
NORMAS DE COMPETENCIA Y NORMAS ACERCA DE LA COMPETENCIA. ELUDIENDO LAS REGLAS CONSTITUTIVAS*
}

\author{
María Beatriz Arriagada Cáceres *** \\ Universidad Diego Portales \\ mbeatriz.arriagada@gmail.com
}

\begin{abstract}
RESUMEN. El objetivo de este trabajo es mostrar que para ofrecer una adecuada explicación de las normas jurídicas de competencia no es necesario ni conveniente considerar que ellas son reglas constitutivas. En la primera y segunda parte del texto se analizan críticamente dos diversas estrategias que los teóricos del derecho han usado para explicar estas normas en función de la noción de regla constitutiva poniendo de relieve por qué ninguna de ellas es adecuada. En la tercera parte del texto, se introducen las bases de una explicación que, al prescindir de la noción de regla constitutiva, es más apropiada para elucidar las normas jurídicas de competencia y para distinguirlas de las normas que regulan el ejercicio de la competencia que denomino normas jurídicas acerca de la competencia.
\end{abstract}

Palabras clave: normas de competencia, normas regulativas, reglas constitutivas.

\section{Norms of Competence and Norms about Competence. Escaping from the Constitutive Rules}

ABSTRACT. The aim of this article is to show that, in order to provide an adequate explanation of the legal competence norms, it is neither necessary nor convenient to consider that they are constitutive rules. In the first and second part of the text, two different strategies that law theorists have used to explain these norms in terms of the notion of constitutive rule are critically analyzed, highlighting why none of them are adequate. The third part of the text introduces the basis for an explanation which, by dispensing with the notion of constitutive rule, is more appropriate to elucidate the legal norms of competence and to distinguish them from the norms regulating the exercise of competence which I call legal norms about competence.

Keywords: competence norms, regulative norms, constitutive rules.

* Fecha de recepción: 19 de enero de 2017. Fecha de aceptación: 10 de marzo de 2017.

Este trabajo corresponde a resultados del proyecto financiado por el Fondo Nacional de Desarrollo Científico y Tecnológico, FONDECYT de iniciación núm. 11150372 «Análisis de la tensión entre el concepto y el fundamento de los derechos fundamentales a partir de las ideas de Fernando Atria sobre las diferencias entre los derechos civiles y políticos y los derechos sociales».

$* *$ Doctora en derecho por la Universidad de Chile. Profesora e investigadora de la Facultad de Derecho de la Universidad Diego Portales, Santiago Chile. Investigadora del Centro de Investigaciones de Filosofía del Derecho y Derecho Penal, Escuela de Derecho, Universidad de Valparaíso, Chile. 


\section{INTRODUCCIÓN}

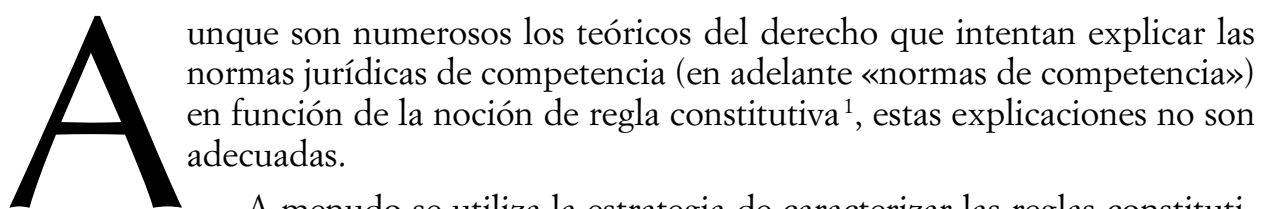

A menudo se utiliza la estrategia de caracterizar las reglas constitutivas por oposición a las reglas regulativas para luego afirmar que las normas de competencia son una especie de las primeras. Esta estrategia, seguida por autores como ROSS, HART, ALCHOURRÓN y BULYGIN, presenta el problema de que no logra superar la controversia sobre cuál es el criterio correcto para distinguir las reglas constitutivas de las regulativas; concretamente, si la diferencia reside en el modo en que las reglas se relacionan con las acciones o actividades a que se refieren o en las acciones o actividades referidas por las reglas. Por otra parte, aunque estos autores diferencian claramente las normas de competencia de las normas que regulan el ejercicio de la competencia, ninguno consigue ofrecer una explicación sistemática de las normas de competencia.

El esfuerzo más sistemático dirigido a explicar las normas de competencia en función de la noción de regla constitutiva utiliza una estrategia diferente. En lugar de caracterizar las reglas constitutivas por oposición a las regulativas, adopta un determinado concepto de regla constitutiva para luego explicar, en función de ese concepto, las normas de competencia. Me refiero al trabajo de Jordi FERRER Las normas de competencia. Un aspecto de la dinámica jurídica ${ }^{2}$. Esta estrategia falla porque, al extender el concepto de competencia y el de normas de competencia a los actos que no son normativos en sentido estricto, amplía inapropiadamente los conceptos de validez e invalidez y, al excluir de los conceptos de competencia y de normas de competencia los límites procedimentales y sustantivos de la validez, no logra explicar claramente qué tipo de normas son las que establecen tales límites.

Las razones por las cuales estas estrategias fracasan justifican ensayar una explicación de las normas de competencia que prescinda de la noción de regla constitutiva.

Antes de comenzar, debo aclarar que, al hablar de normas o reglas ${ }^{3}$, asumo las siguientes tesis:

i) Una norma no es equivalente a las palabras que se usan para su formulación ${ }^{4}$. Se deben distinguir las normas de las disposiciones normativas en que se expresan ${ }^{5}$.

ii) Que una expresión lingüística sea la formulación de una norma y el tipo de norma que ella expresa no depende de su aspecto sino del modo en que se usan las palabras ${ }^{6}$.

${ }^{1}$ Como me interesan los esfuerzos de los teóricos del derecho por explicar las normas jurídicas de competencia en función de la noción de regla constitutiva, no analizo, o al menos no directamente, los trabajos de filósofos que, con objetivos diversos, estudian las reglas constitutivas, por ejemplo, CONTE, 1989, 1995 y 2001, CARCATERRA, 1979 y 2014 y ROVERSI, 2014, o la diferencia entre reglas constitutivas y regulativas, por ejemplo, SEARLE, 1964, 2007 (1969) y 1997 (1995), y VON Wright, 1970 (1963): $26-27$ y (1979) [1971]: 177-179.

2 FERRER, 2000.

3 Usaré los términos «regla» y «norma» como sinónimos.

${ }^{4}$ VON WRIGHT, 1970 (1963): 109.

5 GUASTINI, 2014 (2013): 77-78.

6 VON Wright, 1970 (1963): 110 y 117-119. Asumo que las normas son el resultado de cierto uso del lenguaje; AlCHOURRÓN y BuLYGIN, 1991 (1981): 122-123. Pero comparto que: i) no es plausible que una norma 
iii) El significado de una disposición y, por tanto, la norma que ella expresa depende de un acto de interpretación ${ }^{7}$ y de la práctica interpretativa ${ }^{8}$.

\section{LAS NORMAS DE COMPETENCIA COMO REGLAS CONSTITUTIVAS, DIFERENTES E IRREDUCTIBLES A LAS REGLAS REGULATIVAS: ROSS, HART, ALCHOURRÓN Y BULYGIN}

Una de las estrategias para explicar las normas de competencia en función de la noción de regla constitutiva consiste en: i) caracterizar las reglas constitutivas por oposición a las reglas regulativas, y ii) argumentar que las normas de competencia son una especie de las primeras. El objetivo de esta parte es analizar críticamente esta estrategia y explicar por qué no es adecuada.

\subsection{La propuesta de Ross}

\subsubsection{Dos criterios diversos para distinguir las reglas constitutivas de las reglas regulativas}

Aunque en su libro más conocido Ross defendió la tesis reduccionista de que las normas de competencia son normas de conducta indirectamente expresadas ${ }^{9}$, más tarde habría cambiado de opinión para afirmar que ellas son una especie de las reglas constitutivas, diferentes e irreductibles a las normas de conducta que ahora denomina regulativas.

La distinción entre tipos de reglas es presentada como una que se funda en el modo en que las reglas se relacionan con la actividad a la que se refieren. Pero este criterio parece confundirse con otro diferente: el tipo de actividad al que las reglas se refieren:

Aparcar un coche es una actividad «natural»; quiero decir con esto que es una actividad cuya ejecución es independiente lógicamente de las reglas que la gobiernan. Los coches eran aparcados antes de que existieran reglas de aparcamiento, y sería un absurdo obvio si yo dijera que no podía aparcar mi coche a causa de no haber reglas de aparcamiento en esa ciudad. En cambio, jugar al ajedrez no es una actividad «natural». Jugar al ajedrez es realizar ciertas acciones de acuerdo con las reglas del ajedrez. Las acciones del juego consisten en «movimientos» que no tienen significado ni propósito excepto el de reglas del ajedrez. Un movimiento se realiza moviendo una pieza de madera sobre un cuadrado. Que la pieza de un peón, y que su cambio de lugar sea un «movimiento» solo puede entenderse si se interpreta la acción en términos de las reglas del ajedrez ${ }^{10}$.

sea identificada con un acto lingüístico; ii) la concepción expresiva responde a la pregunta de ante qué condiciones podemos afirmar que una norma existe, pero no a la pregunta de qué tipo de entidad es una norma. Tiene por objeto el proceso de producción de normas, pero nada dice sobre la naturaleza del producto; iii) ese producto es una entidad del lenguaje (un enunciado significante), y iv) los significados (las normas) dependen de la interpretación de los enunciados; GUASTINI, 2014 (2013): 293 y ss.

7 GUASTINI, 2014 (2013): 79. La existencia de una norma depende de un acto lingüístico de formulación y de un acto lingüístico de interpretación; GUASTINI, 2014 (2013): 302.

8 Los signos solamente pueden servir de guía en la medida que exista un uso estable, una práctica; WITTGENSTEIN, 2008 (1953): parágrafos 199 y 202.

9 Ross, 2005 (1958): 58-60, 78-79, 109-114 у 205-207.

10 Ross, 2000 (1968): 68-69. 
La diferencia esencial recién descrita puede expresarse, según Ross, llamando a las reglas de aparcar regulativas y a las reglas del ajedrez constitutivas ${ }^{11}$.

En el caso de las reglas constitutivas, los dos criterios (el modo en que las reglas se relacionan con la actividad a que se refieren y el tipo de actividad referida por las reglas) son en realidad uno: como las acciones del juego son constituidas por las reglas del ajedrez, las acciones de este juego no son naturales.

Como las reglas del ajedrez definen el juego como institución y suministran las condiciones lógicamente necesarias para hacer los movimientos en que el juego consiste, no pueden, en estricto sentido, ser violadas. Su no seguimiento implica que no se está jugando ajedrez ${ }^{12}$. En este contexto, Ross afirma que los actos jurídicos como promesas, testamentos, leyes, juicios o actos administrativos no son naturales sino actos concebibles solamente como constituidos por reglas jurídicas ${ }^{13}$. Las normas que confieren competencia jurídica para realizar estos actos serían entonces una especie de las reglas constitutivas.

Aunque la distinción entre tipos de reglas aparenta ser clara, para comprobar que no lo es basta observar que Ross no precisa de qué modo las reglas regulativas se relacionan con la actividad a que ellas se refieren. Solo afirma que se refieren a actividades naturales cuya ejecución es independiente lógicamente de las reglas que las gobiernan.

La cuestión es importante porque permite dudar que el criterio para distinguirlas de las reglas constitutivas sea el modo en que se relacionan con la actividad a que se refieren. Este criterio no puede, en este caso, fundirse con el que apela al tipo de actividad al que las reglas se refieren. Si el criterio es el modo en que las reglas se relacionan con la actividad, las reglas regulativas podrían referirse tanto a actividades naturales como no naturales. Faltaría precisar de qué modo se relacionan con estas actividades: qué significa gobernar una actividad. Si el criterio es, en cambio, el tipo de actividad referida por las reglas, las reglas regulativas no podrían referirse a actividades que no son naturales.

Aunque Ross no descarta explícitamente que las reglas regulativas puedan referirse a actividades no naturales, su caracterización de estas reglas permite suponer que esta posibilidad está excluida. Esto sugiere que el criterio para distinguir reglas es el tipo de actividad al que ellas se refieren. Como consecuencia, si hubiera reglas que se refieren a conductas no naturales, tendrían que ser constitutivas. Pero esta conclusión no puede obtenerse de manera segura porque Ross está utilizando de manera confusa dos criterios diversos para trazar la distinción entre tipos de reglas.

\subsubsection{ROSS y SEARLE}

Llegados a este punto la referencia obligada es a SEARLE, no porque haya sido el responsable de que la distinción entre reglas regulativas y constitutivas se pusiera de

\footnotetext{
11 Ibid., 69.

12 Ibid., 69-70.

13 Ibid., 72.
} 
moda ${ }^{14}$, sino porque Ross afirma que, después de haber escrito sobre esta distinción, encontró la misma en John SEARLE ${ }^{15}$.

El criterio searliano para distinguir estos dos tipos de reglas es el tipo de conducta al que las reglas se refieren. Las reglas constitutivas no solamente constituyen conductas cuya existencia es lógicamente dependiente de tales reglas. También regulan las conductas por ellas constituidas:

Some rules regulate antecedently existing forms of behavior. For example, the rules of polite table behavior regulate eating, but eating exists independently of these rules. Some rules, on the other hand, do not merely regulate but create or define new forms of behavior: the rules of chess, for example, do not merely regulate an antecedently existing activity called playing chess; they, as it were, create the possibility of or define that activity. The activity of playing chess is constituted by action in accordance with these rules. Chess has no existence apart from these rules [...]. Regulative rules regulate activities whose existence is independent of the rules; constitutive rules constitute (and also regulate) forms of activity whose existence is logically dependent on the rules ${ }^{16}$.

Las reglas constitutivas: i) crean o definen nuevas formas de conducta; ii) pueden ser parafraseadas naturalmente de la forma «X cuenta como $\mathrm{Y}$ en el contexto C» (donde $Y$ es un término de especificación, no de apreciación), y iii) pueden aparecer como una verdad analítica basada en el significado de la actividad que ellas definen porque tienen un carácter casi tautológico. Estas características permiten diferenciar a las reglas constitutivas (que también regulan) de las reglas que, en cambio, son puramente regulativas ${ }^{17}$.

SEARLE no afirma que las reglas constitutivas sean, a la vez, reglas regulativas, como cree BULYGIN $^{18}$, sino que las reglas que constituyen actividades también regulan esas actividades. El problema es, como afirma RAZ, que no explica de qué manera lo hacen ${ }^{19}$. SCHAUER ensaya una explicación argumentando que, si bien las instituciones son establecidas por conjuntos de reglas constitutivas, estas pierden su carácter constitutivo dentro de esas instituciones y sirven para regular conductas previamente definidas ${ }^{20}$. Al decir esto parece distinguir, como VON WRIGHT, la perspectiva del juego (los movimientos correctos) de la perspectiva de la actividad de jugarlo (los movimientos permitidos, prohibidos y obligatorios) ${ }^{21}$. Pero esto tampoco es lo que SEARLE quiere decir.

El hecho de que SEARLE no explique de qué manera las reglas constitutivas regulan la conducta que ellas mismas constituyen es un indicio de que el criterio para distinguir tipos de reglas no es el modo en que estas se relacionan con la actividad a la que se refieren sino el tipo de actividad referida por las reglas. Esto se confirma si se examina la conexión que existe entre la distinción de reglas puramente regulati-

14 Bulygin, 1991 (1988): 492.

15 Ross, 2000 (1968): 69, nota 10 de ese trabajo. La referencia es a SEARLE, 1964.

16 Searle, 1964: 55. Lo destacado es mío. Vid. también SEArLe, 2007 (1969): 43.

17 SEARLE, 2007 (1969): 43-45.

18 Según este autor, SEARLE no aclara cómo es posible que las reglas constitutivas sean, por un lado, definiciones o enunciados analíticos basados en el significado de los términos así definidos y, por el otro, reglas regulativas de las actividades por ellas definidas; BULYGIN, 1991 (1988): 492.

19 RAZ, 1991 (1975): 127.

20 SCHAUER, 2004 (1991): 63.

21 Von Wright, 1970 (1963): 26. 
vas y constitutivas y la de hechos brutos e institucionales. Los hechos brutos, como conducir un automóvil, son aquellos cuya existencia no depende lógicamente de la existencia de ninguna regla aunque pueden ser regulados por reglas regulativas como la que ordena conducir por el lado derecho de la calzada. Necesitan del lenguaje para que podamos enunciarlos, pero su existencia no depende del lenguaje ni de ninguna otra institución. Los hechos institucionales, como el dinero, las promesas, el juego de ajedrez o una acción legislativa, solo pueden existir dentro de las instituciones humanas. Su existencia depende lógicamente de la existencia de una regla o sistema de reglas constitutivas ${ }^{22}$.

SEARLE explica de qué manera las reglas constitutivas, cuya forma lógica es «X cuenta como Y», crean hechos institucionales ${ }^{23}$. Sin embargo, como Ross, no explica qué significa que una regla regulativa regule un hecho bruto. Tampoco explica el modo en que las reglas constitutivas regulan los hechos institucionales que ellas crean. Una regla que regula la conducción (ordenando hacerlo por el lado derecho de la calzada) es regulativa porque la conducción puede existir antes de la existencia de esa regla. Las reglas del ajedrez son, en cambio, constitutivas porque no regulan una actividad previamente existente sino crean la posibilidad misma de realizarla. Lo que sea jugar ajedrez queda en parte constituido por la actuación según esas reglas y no seguirlas implica no jugar ajedrez ${ }^{24}$.

El evidente descuido del aspecto regulativo de las reglas constitutivas y del modo en que las reglas regulativas se relacionan con los hechos brutos admite ser interpretado como una opción por un criterio para distinguir entre reglas regulativas y constitutivas: el tipo de actividad o hecho al que las reglas se refieren.

Si la distinción de Ross es, como cree, la misma que la de SEARLE, tendríamos que concluir que, de acuerdo con Ross, las reglas regulativas solamente pueden referirse a actividades naturales (hechos brutos) y que, en consecuencia, toda regla que se refiere a una actividad no natural (hecho institucional) es constitutiva ${ }^{25}$.

La cuestión es importante para las normas de competencia si estas son, como sugiere Ross, constitutivas en el mismo sentido de SEARLE. Si toda regla que se refiere a

22 SEARLE, 1964: 54-58; 2007 (1969): 43, 58-61, y 1997 (1995): 44-47.

23 La creación de estos hechos consiste en asignar a algunos fenómenos o entidades (X) un nuevo estatus (Y) y con él una función o un conjunto de funciones cuyo cumplimiento no depende de los rasgos intrínsecos del fenómeno sino de nuestro acuerdo o aceptación. Crear una función de estatus consiste en conferir un poder nuevo o ejecutar alguna operación veritativo-funcional sobre la creación de un poder. Como en la base de la estructura jerárquica de los hechos institucionales siempre hay hechos brutos, en el primer desplazamiento el término $\mathrm{Y}$ impone a X un estatus que va más allá de sus propiedades físicas. El paso siguiente impone funciones de estatus a entidades a las que ya se había impuesto una función, especialmente actos de habla. Luego estos se usan para imponer funciones de estatus a entidades que no son actos de habla, por ejemplo, a la gente; SEARLE, 1997 (1995): 58-65, 67-68, 72, 83-89, 94-96, 98, 108 y 116.

24 Ibid., 45. Esto parece confirmar que la distinción de SEARLE entre hechos brutos e institucionales es ontológica, como afirma GUASTINI, 1984: 306.

${ }_{25}$ Podría argumentarse que, aunque Ross distingue, como SEARLE, las actividades naturales de las instituciones, no sugiere que las actividades institucionales sean ontológicamente distintas de las naturales. Son simplemente acciones a las cuales las reglas constitutivas confieren significado; GUASTINI, 1984: 308 . Pero el hecho de que Ross omita decir el modo en que las reglas regulativas se refieren a las actividades naturales, permite seguir afirmando que Ross está usando dos criterios diferentes para distinguir a las reglas constitutivas de las regulativas. 
un acto jurídico (no natural o institucional) es constitutiva, el carácter constitutivo de las normas de competencia se deriva del tipo de acto al que ellas se refieren. Si las reglas constitutivas también regulan las actividades que constituyen, como afirma SEARLE, la constitución de tales actividades admite ser vista como un mero paso intermedio en el trayecto dirigido a su regulación. ¿Qué tan diferente es esto a decir que las normas de competencia son normas de conducta indirectamente expresadas? ¿Es plausible que Ross no haya cambiado realmente de opinión?

\subsection{3. ¿Las normas de competencia como reglas constitutivas?}

La interpretación de las normas de competencia como normas de conducta indirectamente expresadas es posible, según Ross, si las normas de competencia tienen como efecto la anulabilidad o la responsabilidad. Lo primero significa que los tribunales deben aplicar solo las reglas de conducta creadas de acuerdo con las condiciones establecidas en las normas de competencia descartando, como nulas, las que no ha cumplido dichas condiciones. Lo segundo significa que los tribunales deben ordenar sanciones contra el responsable por el exceso en la competencia ${ }^{26}$. La interpretación de las normas de competencia como normas diferentes e irreductibles a las normas de conducta supone, en cambio, que ellas son distinguibles por la diversa consecuencia que se sigue de su respectiva observancia e inobservancia: invalidez y responsabilidad. Precisamente porque el criterio para distinguirlas es el modo en que se relacionan con los actos a que se refieren, las normas de conducta también pueden referirse a actos jurídicos:

Las reglas de competencia definen cuáles son las condiciones necesarias para crear una nueva norma legal. Si un intento de legislación no satisface estas condiciones, se dice que el resultado es inválido o nulo. Un conjunto de reglas de competencia constituye una unidad que puede dividirse usualmente en tres partes: (1) reglas que determinan la competencia personal, indicando qué personas están calificadas para participar en el proceso creador de nuevas leyes; (2) reglas que determinan la competencia de procedimiento, pues definen el procedimiento a seguir; y (3) reglas que determinan la competencia de materia, indicando aquellos asuntos de los que puede ocuparse el directivo en cuestión ${ }^{27}$.

Es importante comprender esta distinción entre la norma de competencia y la norma de conducta que regula el ejercicio de tal competencia. Mientras que exceder la norma de competencia produce invalidez, violar la norma de conducta no afecta a la validez del acto jurídico, sino que encierra una responsabilidad, como cualquier otra violación de una obligación ${ }^{28}$.

Además de distinguir la competencia de su regulación mediante normas que imponen deberes, Ross afirma que las normas de competencia definen las condiciones necesarias y suficientes para crear nuevas normas ${ }^{29}$. Su propuesta tiene dos virtudes: i) diferencia tres tipos de normas de competencia (personal, procedimental y material), y ii) distingue claramente estas normas de las normas que regulan el ejercicio de la competencia.

\footnotetext{
26 Ross, 2005 (1958): 78.

27 Ross, 2000 (1968): 124.

28 Ibid., 168-169.

29 Ross 1991b (1961): 77; 1991c (1969): 43, y 1991d (1972): 111.
} 
El reconocimiento de que las normas regulativas pueden referirse a actos jurídicos que producen normas muestra que las normas de competencia rossianas no son constitutivas en el sentido de SEARLE. La pregunta es entonces si pueden considerarse constitutivas en el sentido de Ross. Este cree que sí porque, a su parecer: i) los enunciados en los que se ejercita la competencia se llaman actos jurídicos y un acto jurídico es, como un movimiento de ajedrez, un acto humano que nadie puede realizar como ejercicio de sus facultades naturales, y ii) las normas de competencia son, como las reglas de los juegos, constitutivas ${ }^{30}$. Sin embargo, hay dos razones que desaconsejan la consideración de las normas de competencia como una especie de las reglas constitutivas en la explicación de Ross.

La primera es que esta consideración nos devuelve al problema inicial: Ross utiliza de manera confusa dos criterios diversos para distinguir entre reglas regulativas y constitutivas. Como consecuencia, su afirmación de que las reglas regulativas se refieren a actividades naturales cuya ejecución es lógicamente independiente de las reglas que las gobiernan, conduce a la conclusión inconsistente de que las normas de conducta que regulan el ejercicio de la competencia no son regulativas sino constitutivas.

La segunda razón es que la explicación rossiana parece ignorar que las normas de competencia son diferentes a las reglas constitutivas de los juegos por lo que aquellas tienen en común con las normas jurídicas regulativas.

Ross compara las reglas constitutivas de los juegos con las que llama cuasi-mandatos. La forma en que define e ilustra a estas últimas (reglas legales que son directivos heterónomos como la prohibición de homicidio) es indicativa de que está pensando en normas jurídicas regulativas. A su parecer, ambas reglas son semejantes porque son impersonales, esto es, no derivan su autoridad de ninguna persona sino de un sistema de normas. La diferencia reside en que mientras los cuasi-mandatos son heterónomos, esto es, impuestos al individuo con independencia de su aceptación o reconocimiento, las reglas constitutivas de los juegos son autónomo-heterónomas ${ }^{31}$. La pregunta pertinente es si esta característica de las reglas de los juegos está presente en las normas de competencia.

Ross parece creer que sí desde el momento en que afirma que: i) algunas reglas legales constituyen actos jurídicos del mismo modo en que un movimiento de ajedrez es constituido por las reglas del ajedrez ${ }^{32}$, y ii) los directivos impersonales y heterónomo-autónomos no solamente incluyen las reglas de los juegos sino también otras regulaciones semejantes fundadas en el acuerdo recíproco ${ }^{33}$. Pero para responder a la pregunta planteada se debe prestar atención a la razón por la cual las reglas de los juegos se consideran autónomo-heterónomas. Son autónomas porque se cumplen por un sentimiento espontáneo o voluntario de obligación que se deriva de la aceptación recíproca de los jugadores y son heterónomas porque, una vez acordadas, los jugadores no pueden modificarlas unilateralmente ${ }^{34}$.

\footnotetext{
30 Ross, 2000 (1968): 168.

31 Ibid., 62-68.

32 Ibid., 72.

33 Ibid., 68.

34 Ibid., 64, 70-71.
} 
Esto sugiere que Ross, a diferencia de SEARLE, apunta en la misma dirección de VON WRIGHT: una vez que se está jugando, los movimientos incorrectos se entienden como prohibidos y cuando existe un único movimiento correcto, este se entiende como obligatorio $^{35}$. Las reglas de los juegos tendrían entonces una dimensión regulativa que depende de que se quiera jugar el juego ${ }^{36}$. Sin embargo, no puede decirse lo mismo de las normas de competencia. Aunque estas puedan considerarse autónomas en el sentido de que su dimensión regulativa o la «obligación» de someterse a ellas solamente surge cuando alguien quiere producir una norma válida, ellas no pueden, en general, modificarse por acuerdo. Podrían modificarse por el acuerdo de las autoridades que las han emitido, pero lo mismo podría decirse de las reglas jurídicas regulativas.

El hecho de que Ross no advierta que las reglas constitutivas del ajedrez son diferentes a las normas de competencia por lo que estas tienen en común con las reglas jurídicas regulativas sumado a la comprobación de que confunde dos criterios diversos para distinguir las reglas constitutivas de las regulativas sugiere que, para ofrecer una adecuada explicación de las normas de competencia no es necesario ni conveniente considerar que son una especie de las reglas constitutivas. Antes de llegar a esta conclusión examinemos otro de los esfuerzos más conspicuos de justificar esta consideración.

\subsection{La propuesta de HART, AlChOURRón y BULYGIN}

El esfuerzo más importante por distinguir las reglas constitutivas de las regulativas en función del modo en que se relacionan con las acciones o actos a que se refieren es iniciado por HART y continuado por AlCHOURRÓN y BULYGIN. Aunque HART aparenta seguir una senda como la aquí sugerida (prescindir de la noción de regla constitutiva para explicar las normas de competencia), su propuesta, como lo confirman sus continuadores, implica la tesis de que las normas de competencia son reglas constitutivas o, en sus términos, definiciones.

\subsubsection{La propuesta de HART}

HART distingue las reglas que imponen deberes de las reglas que confieren poderes en función del modo en que ellas se relacionan con las acciones o actos a que se refieren. Mientras las primeras exigen que las personas actúen de determinados modos, las segundas definen la manera de realizar válidamente ciertos actos ${ }^{37}$.

35 VON WRIGHT, 1970 (1963): 26. Tengo, en cambio, bastantes dudas de si VON WRIGHT compartiría la idea rossiana de que las reglas de los juegos son autónomas en el sentido de que surgen de la aceptación de los jugadores.

36 Por eso se parecen a las reglas técnicas, GonZÁlez LAGIER, 2001: 51-52. No es claro, sin embargo, que VON WRIGHT haya mantenido que las reglas definitorias o constitutivas tienen una dimensión (o pueden ser vistas desde una perspectiva) regulativa. Posteriormente se refirió a la distinción entre normas regulativas y constitutivas en términos de reglas primarias y secundarias sin hacer referencia al punto de vista que autoriza a ver las acciones que integran la práctica social definida por reglas constitutivas como prohibidas, obligatorias o permitidas, VON WRIGHT, 1979 (1971): 177-179.

37 HART, 2009 (1961): 34-35. 
Esta diferencia se manifiesta en la diversa consecuencia que se sigue de su respectiva inobservancia: sanción y nulidad. Cuando se trata de reglas que imponen deberes, es posible distinguir claramente la regla que obliga a determinada conducta de la sanción establecida en caso de su transgresión. Cuando se trata, en cambio, de una regla que confiere poderes, no es lógicamente posible distinguir la regla (que establece condiciones para la validez jurídica) de la nulidad; esta es parte de la regla misma de este tipo de una manera distinta a como el castigo está ligado a una norma que impone deberes $^{38}$.

Lo que HART no aclara es si la necesaria vinculación que existe entre las reglas que confieren poderes y la nulidad se puede afirmar en sentido inverso: si la nulidad está necesariamente conectada con estas reglas.

Parte del problema se origina porque HART no profundiza en el análisis de las reglas que confieren poderes ni sistematiza su clasificación. En diferentes pasajes se refiere a ellas como reglas que confieren potestades públicas o privadas a determinados sujetos $^{39}$, reglas que condicionan el ejercicio válido de potestades previamente conferidas $^{40}$ o reglas que establecen las condiciones de la validez de ciertos actos ${ }^{41}$. En otros pasajes afirma que las mismas reglas que confieren poderes definen o podrían definir el procedimiento $\mathrm{u}$ otras condiciones para su ejercicio válido ${ }^{42} \mathrm{y}$, a veces, en sentido opuesto, sostiene que los diversos aspectos de las potestades públicas y privadas (la potestad misma, el procedimiento, otras condiciones de su ejercicio y sus efectos) estarían entregados a diferentes tipos de reglas pertenecientes a una misma categoría ${ }^{43}$.

De lo que, sin embargo, no cabe duda es que el criterio para distinguir las reglas que confieren potestades de las que imponen deberes no es el tipo de acción o acto al que las reglas se refieren. El reconocimiento de que los actos cuya realización válida es definida por normas que confieren poderes pueden ser adicionalmente normados por reglas que imponen deberes ${ }^{44}$ evidencia que el criterio usado para distinguir estos tipos de reglas es el modo en que ellas se relacionan con los actos o acciones a que se refieren.

El asunto se complica cuando se introduce la distinción de reglas primarias y secundarias que es solo aparentemente coincidente con la de reglas que imponen obligaciones y reglas que confieren poderes ${ }^{45}$. Aunque HART afirma que las reglas primarias imponen deberes y las secundarias confieren potestades públicas o privadas, no parece posible dejar de notar que la regla secundaria de reconocimiento no confiere potestad alguna y que su no seguimiento no produce nulidad sino la imposibilidad de identificar las normas del sistema ${ }^{46}$. Incluso es dudoso que esta regla sea secundaria porque no se

38 Ibid., $43-44$

39 Ibid., 35, 36, 48, 99.

40 Ibid., 38 y 39 .

${ }^{41}$ Ibid., 35 y 44

42 Ibid., 40, 45, 46, 47, 51,119 y 120.

${ }^{43}$ Ibid., 36, 37 y 39 .

44 Ibid., 37.

${ }^{45}$ La distinción entre normas que imponen deberes y que confieren poderes en términos de reglas primarias y secundarias también se encuentra en RUIZ MANERO, 2005: 64-66.

46 FerRer, 2000: 79-80. En contra, Vilajosana, 2010: 104-105. 
refiere a reglas primarias sino a las secundarias al definir los criterios últimos de validez jurídica ${ }^{47}$.

Esta clasificación de las reglas en primarias y secundarias trae consigo una clasificación de las acciones o actos:

Las reglas del primer tipo se refieren a acciones que implican movimiento o cambios

físicos; las del segundo prevén actos que conducen no simplemente a movimiento o cambio

físico, sino a la creación o modificación de deberes u obligaciones ${ }^{48}$.

Como todas las acciones son indudablemente físicas, la diferencia residiría en si son puramente físicas o son, además de físicas, conducentes a la creación o modificación de deberes. El criterio para distinguirlas parece ser si su realización y las consecuencias que de ello se siguen han sido previstas o definidas por reglas secundarias. Por su parte, mientras las reglas secundarias definen algo (las condiciones y límites de la validez de ciertos actos o los criterios últimos de validez del sistema), las reglas primarias que imponen deberes exigen comportarse de cierto modo.

El criterio para diferenciar estas reglas no es el tipo acción o acto al que ellas se refieren porque las reglas primarias pueden referirse tanto a acciones puramente físicas como a actos conducentes a la creación de derechos y obligaciones ${ }^{49}$. Pero el criterio tampoco puede ser el modo en que las reglas se relacionan con las acciones o actos a que se refieren porque la regla secundaria de reconocimiento no se refiere a acciones o actos. La clave parece ser restringir el análisis a las reglas secundarias que confieren poderes excluyendo la regla de reconocimiento. Esta es justamente la estrategia de ALCHOURRÓN y BULYGIN.

\subsubsection{La propuesta de ALCHOURRÓN y BULYGIN}

ALCHOURRÓN y BulYGin distinguen claramente las normas (de conducta, regulativas o prescriptivas) de las definiciones ${ }^{50}$. Aunque ambas se asemejan porque son expresiones de un acto de voluntad, en el discurso jurídico desempeñan funciones muy diferentes ${ }^{51}$. Como las normas cumplen una función prescriptiva (guiar conductas), es esencial que sea posible cumplirlas e incumplirlas. Tienen entonces que ser sintéticas, esto es, referirse a situaciones o estados de cosas contingentes, no necesarias o imposibles. Las definiciones, en cambio, crean siempre una imposibilidad y dan lugar a enunciados necesarios o analíticos. Como no se refieren a conductas o hechos, no podrían ser obedecidas o violadas ${ }^{52}$.

Las definiciones también pueden diferenciarse de las normas usando la distinción entre nulidad y castigo que sirvió a HART para deslindar las reglas que confieren poderes de las reglas primarias de obligación. Si una definición establece los requisitos que debe reunir un acto, un documento o una norma, su ausencia determinará la nulidad

\footnotetext{
47 Vid. HART, 2009 (1961): 119 y 132 y ss., y 1980: 5 y 7.

48 HART, 2009 (1961): 101.

49 Ibid., 120.

50 AlCHOURRÓn y Bulygin, 1991 (1983): 439-441.

51 Ibid., 454-455.

52 Ibid., 457-461.
} 
de ese acto, documento o norma. Cuando, en cambio, se trata de normas que imponen obligaciones, o incluso de normas permisivas, no tiene sentido hablar de nulidad. El argumento hartiano de que la nulidad es parte de la regla secundaria mostraría que, en las reglas secundarias, o al menos en las que confieren potestades, hay un ingrediente que no se deja reducir a reglas de conducta porque pertenecen a la categoría de las reglas conceptuales o determinativas, a las definiciones ${ }^{53}$. Aquí se aprecia claramente que la regla de reconocimiento es diferente de las demás reglas secundarias porque no confiere potestades ${ }^{54}$.

$\mathrm{Al}$ argumentar que las definiciones no se refieren a conductas o hechos contingentes, estos autores parecen apuntar en la misma dirección de Ross y SEARLE: las definiciones, a diferencia de las normas, no podrían referirse a actividades naturales o hechos brutos cuya existencia es independiente de las reglas que los gobiernan. Pero ¿es plausible considerar que un acto nulo no es una conducta o que un documento nulo no es un hecho?

Aunque la forma en que lo expresan no es particularmente clara, ALCHOURRÓn y BULYGIN no distinguen las normas de conducta de las definiciones o reglas conceptuales por el tipo de actividad a que ellas se refieren sino por el modo en que se relacionan con la actividad referida. Los requisitos para que un acto o un documento sea válido son necesarios (no contingentes) en el sentido de que, al estar definidos por reglas que confieren poderes, su falta determina la imposibilidad de que ese acto o ese documento sea válido. Pero la realización del acto o la ejecución del documento es tan contingente como aparcar un automóvil.

La localización del criterio de distinción en la norma y no en la actividad referida por ella es posteriormente confirmada por BULYGIN, cuya tesis es que las normas de competencia son una especie del género de las definiciones ${ }^{55}$. Allí afirma que, pese a que autores como HART y ROSS no han extraído todas las consecuencias que se siguen de sus afirmaciones, sus análisis permiten concluir que las normas de competencia definen ciertos tipos de conducta (HART) y son reglas constitutivas (ROSS). Mientras las normas de conducta (equivalentes a las prescripciones de VON WRIGHT) son el paradigma de lo que ROSS y SEARLE llaman reglas regulativas porque regulan la conducta humana al exigir, excluir o autorizar ciertas acciones o actividades, las reglas conceptuales (equivalentes a las reglas determinativas de VON WRIGHT) son constitutivas en el sentido que ROSS y SEARLE dan a este término porque definen modelos de conducta que no existen fuera de esas reglas ${ }^{56}$.

BULYGIN prefiere decir que las reglas conceptuales, determinativas o constitutivas definen modelos de conducta que no existen fuera de esas reglas en lugar de afirmar que se refieren a conductas que no son naturales (hechos brutos). Como el foco no está en el tipo de conducta sino en la regla, nada impide decir que las reglas regulativas pueden regular conductas definidas por reglas constitutivas. De modo semejante a

53 Ibid., 461-463. (1976)

${ }^{54}$ La regla de reconocimiento es simplemente una definición, una regla conceptual, BuLYGIN, 1991

55 Bulygin, 1991 (1988).

56 Vid. BulYGin, 1991 (1988): 487-495, y VON WRIGHT, 1970 (1963): $27-27$. 
como HART distingue las acciones que implican movimiento o cambios físicos de los actos que, al ser previstos por reglas secundarias, también conducen a la creación o modificación de deberes u obligaciones» ${ }^{57}$, BULYGIN distingue los actos ordinarios de los actos jurídicos como contratos o testamentos cuya forma es definida por normas de competencia, afirmando que estos últimos pueden ser prohibidos o permitidos por normas de conducta ${ }^{58}$.

Finalmente, junto con reiterar la relación que existe entre la distinción entre reglas regulativas y constitutivas y la de proposiciones sintéticas y analíticas, BULYGIN retoma el argumento hartiano sobre la imposibilidad de asimilar la noción de nulidad a la de sanción para afirmar, dando el paso que HART no dio, que la noción de la nulidad solo tiene sentido en relación con las reglas constitutivas que definen un cierto concepto o una actividad como el juego del ajedrez ${ }^{59}$. Esto implica que entre reglas constitutivas y nulidad existe una doble relación necesaria: i) la existencia de la regla que define las condiciones para que una norma, acto o documento sean válidos depende de la nulidad porque sin esta no habría tal definición (el argumento hartiano), y ii) solo tiene sentido hablar de nulidad en relación con las reglas constitutivas que definen tales condiciones ${ }^{60}$.

$\mathrm{Al}$ decir que la noción de la nulidad solamente tiene sentido en relación con las reglas constitutivas que definen un cierto concepto o una actividad como el juego del ajedrez, BULYGIN abre un espacio para la crítica porque hay conceptos definidos por reglas que no se refieren a actividades como el juego de ajedrez sino a clases de cosas (bien mueble), clases de sujetos (menor de edad) o clases de acciones (homicidio) respecto de los cuales no tiene sentido predicar validez o invalidez ${ }^{61}$.

A esta crítica puede responderse que la referencia al ajedrez cumple el acotado papel de aclarar que la nulidad está necesariamente conectada con las reglas que definen conceptos o actividades como la producción de normas jurídicas que, en lo que importa, se asemeja al juego de ajedrez. La tesis de BuLYGIN es que las normas jurídicas de competencia no solo definen, como sugiere HART, las condiciones necesarias para producir normas jurídicas válidas, sino también las condiciones suficientes, como afirma Ross. Pero para defender esta tesis basta decir que la nulidad tiene sentido en relación con las normas que definen la producción de normas jurídicas porque los actos jurídicos normativos y sus resultados (las normas) pueden ser calificados como válidos o inválidos según esas normas, así como los movimientos del ajedrez y sus resultados pueden ser calificados como válidos o inválidos según las reglas de ese juego ${ }^{62}$.

BULYGIN apunta en la dirección correcta cuando piensa en las normas de competencia como normas que definen modelos de conducta que no existen fuera de esas

57 HART, 2009 (1961): 101.

58 BuLYGIN, 1991 (1988): 489-490.

59 Ibid., 495-496.

60 Bulygin, 1991 (1988): 496.

61 La crítica a la que me refiero toma solamente una parte de la ya formulada en contra de ALCHOURRÓN y BuLYGIN consistente en que ellos desdibujan la distinción entre las definiciones y las reglas que confieren poderes; vid., por ejemplo, AguiLó, 1990: 277-280.

62 Desde esta perspectiva, cualquier concepto puede estar conectado con la noción de nulidad si forma parte de un enunciado acerca de la producción de normas; por ejemplo «un contrato celebrado por un menor de edad sin autorización de su representante legal es nulo». 
reglas, pero no advierte que, para defender esta tesis, es necesario negar que las normas de competencia son constitutivas en el sentido que ROSS y SEARLE dan a ese término. A diferencia de BulYGIN, SEARLE distingue las reglas regulativas de las constitutivas por el tipo de actividad a que ellas se refieren y Ross confunde este criterio de distinción con el defendido por BULYGIN.

\subsection{Para concluir esta sección}

El análisis crítico de la estrategia de ROSs, HART, ALCHOURRÓn y BULYGIN muestra que ella no es adecuada para explicar las normas de competencia. El intento de hacerlo en función de la noción de regla constitutiva fracasa porque no consigue superar la discusión sobre cuál es el criterio correcto para distinguir las reglas constitutivas de las reglas regulativas.

Por otra parte, aunque estos autores distinguen claramente las normas de competencia (constitutivas) de las normas que gobiernan el ejercicio de la competencia (regulativas), ninguno de ellos realiza un análisis sistemático de las normas de competencia. El único que avanza en esta dirección es Ross al diferenciar tres diversos tipos de normas de competencia. Pero su propuesta es justamente la más problemática porque, al confundir dos criterios diversos para distinguir las reglas constitutivas de las regulativas, admite la conclusión de que las normas que regulan el ejercicio de la competencia no son regulativas sino constitutivas.

La solución de la controversia sobre el criterio correcto para distinguir a las reglas constitutivas de las reglas regulativas ha sido avanzada por GONZÁLEZ LAGIER ${ }^{63}$ al introducir la distinción gradual entre descripciones que interpretan y descripciones que no interpretan la conducta. Desde esta perspectiva: i) las descripciones naturales pueden ser no interpretativas (flexionar un dedo sobre el gatillo) o interpretativas (matar); ii) las descripciones institucionales son siempre interpretativas (cometer un homicidio, jugar al ajedrez), y iii) las descripciones en términos de movimientos corporales están siempre disponibles para cualquier conducta. Esto permitiría: i) distinguir dos tipos de conducta conforme a una regla: la que puede ser descrita de una manera interpretada exista o no la regla en cuestión y la que solamente puede ser descrita de una manera interpretada si existe la regla, y ii) reformular la distinción entre reglas regulativas y constitutivas como una distinción gradual según la cual las reglas constitutivas tienen más fuerza constitutiva que las reglas regulativas:

Una regla es regulativa cuando la conducta conforme con ella puede ser descrita como una conducta no interpretada, como una acción natural interpretada o como una acción institucional. Una regla es constitutiva cuando la conducta conforme con ella solo puede ser descrita como una conducta no interpretada o como una acción institucional ${ }^{64}$.

Aunque GONZÁLEZ LAGIER apunta en la dirección correcta, su perspectiva no sirve para explicar diferenciadamente las normas de competencia y las que regulan el ejercicio de la competencia porque tanto unas como otras serían constitutivas, además de que seguiría pendiente una explicación sistemática de las normas de competencia.

\footnotetext{
63 GonZÁlez Lagier, 1995: 259-263.

64 Ibid., 263.
} 


\section{ELUDIENDO LA DISTINCIÓN ENTRE REGLAS CONSTITUTIVAS Y REGLAS REGULATIVAS: LA PROPUESTA DE JORDI FERRER}

El esfuerzo más sistemático por explicar las normas de competencia en función de la noción de regla constitutiva ha sido desarrollado en el libro Las normas de competencia. Un aspecto de la dinámica jurídica de Jordi FERRER. Aunque la manera en que este entiende las reglas constitutivas consigue eludir la controversia sobre cuál es el criterio correcto para distinguir las reglas constitutivas de las regulativas, su estrategia tampoco es adecuada. El objetivo de esta parte es explicar por qué.

\subsection{Las normas de competencia como reglas constitutivas: eludiendo la controversia sobre el criterio para distinguir las reglas constitutivas de las regulativas}

Las normas de competencia son, según FERRER, reglas constitutivas, pero ellas no se distinguen por el tipo actividad o conducta a que se refieren ni por el modo en que se relacionan con la actividad o conducta referida. Son reglas constitutivas en el sentido de que son emitidas mediante un uso performativo u operativo del lenguaje ${ }^{65}$. Ellas no constituyen actividades o conductas sino el hecho institucional «ser competente» ${ }^{66}$.

Aunque FERRER encuadra este concepto de regla constitutiva en la tipología contiana afirmando que las normas de competencia pertenecen a la clase de las reglas noético-constitutivas ${ }^{67}$, su propuesta es principalmente deudora de una fracción muy acotada de la teoría de SEARLE.

FERRER se aparta de la interpretación de las reglas constitutivas searlianas como definiciones para utilizar, además de la idea muy general de que la creación de hechos institucionales depende de reglas constitutivas, la breve explicación que SEARLE ofrece de los casos en que estas reglas permiten la creación de hechos institucionales mediante la simple declaración de que una función de estatus $(\mathrm{Y})$ se impone a un acto de habla $(\mathrm{X})^{68}$.

El argumento de FERRER es que, como la producción de hechos institucionales depende de la existencia de reglas constitutivas y la emisión de estas depende de actos en los que se hace un uso performativo del lenguaje, se podría decir que, transitivamente, la producción de hechos institucionales (como el hecho de ser competente) depende de la realización de aquellos actos lingüísticos. Las normas de competencia son constitutivas porque constituyen al sujeto de las mismas en competente atribuyéndole la propiedad de «ser competente» para realizar un determinado acto jurídico sobre cierta materia. Como la atribución de una competencia ilimitada o inespecífica carecería de sentido, el aspecto personal de la competencia está siempre unido al aspecto material

65 FERRER, 2000: 147-148.

66 Ibid., 151.

67 Ibid., 152-154.

68 SEARLE, 1997 (1995): 51-52, 70-71 y 127-128. FERRER exagera la importancia del tema al decir que SEARLE sostiene que la producción de hechos institucionales depende, en la mayoría de los casos, de enunciados performativos, FERRER, 2000: 151. Lo que SEARLE afirma es que un gran número de hechos institucionales pueden ser creados mediante expresiones performativas. 
en una misma disposición o al menos conectado indirectamente mediante el recurso a diversas disposiciones jurídicas ${ }^{69}$.

La competencia es definida como la capacidad, atribuida por reglas de un determinado sistema, de producir actos jurídicos válidos de acuerdo con ese mismo sistema. De ello se extraería que: i) la competencia es siempre relativa a un sistema jurídico, y ii) las normas de competencia amplían las posibilidades de actuación de los sujetos poniendo a su alcance resultados institucionales que antes no podían conseguir. FERRER argumenta, siguiendo a SEARLE, que la competencia es una propiedad disposicional institucional que se distingue del mero poder porque depende de la existencia de determinadas reglas ${ }^{70}$.

Respecto del objeto de la competencia, FERRER se aparta de la tesis habitual de que las normas de competencia tienen por objeto actos normativos en sentido estricto para incluir también a los actos jurídicos que no crean ni derogan normas. Esta definición más amplia permitiría dar cuenta de algunas intuiciones básicas de los juristas. Se podría afirmar, por ejemplo, que el secretario judicial es competente para firmar las sentencias junto al juez, que la policía es competente para detener a individuos en determinadas circunstancias, que los funcionarios de las prisiones son competentes para ejecutar las condenas privativas de libertad emitidas por los jueces y que el rey es competente para sancionar y promulgar leyes ${ }^{71}$.

En cuanto a la relación entre competencia y validez, FERRER afirma que las normas de competencia no permiten identificar los actos jurídicos válidos ni las normas jurídicas válidas. De la validez de un acto o de una norma se puede derivar la competencia del sujeto que lo realizó o la dictó, pero no es correcto el paso inverso. La competencia del sujeto que realiza el acto o emite una norma es una condición necesaria pero no suficiente de la de validez de ese acto o norma. Para que esta se dé son necesarias otras condiciones que denomina «condiciones de actualización de la competencia»: observancia de las reglas procesales y el requisito de que no pertenezcan al sistema normas superiores y contradictorias con la que se pretende dictar ${ }^{72}$.

Como las normas de competencia solamente atribuyen a un sujeto la propiedad de «ser competente»: i) ellas confieren competencia para realizar todo tipo de actos jurídicos, y ii) la validez de esos actos no depende exclusivamente de la observancia de las normas de competencia. La consecuencia de i) es que las normas constitutivas de la competencia no pueden distinguirse de las normas regulativas por el tipo de acto al que se refieren. La consecuencia de ii) es que las normas constitutivas de la competencia no pueden distinguirse de las normas regulativas por el modo en se relacionan con los actos a que se refieren.

FERRER rechaza la tesis de que las normas de competencia son constitutivas en el sentido de definiciones de validez ${ }^{73}$. Se aparta del argumento hartiano de que la nuli-

69 FERRER, 2000: 124-125, 127-147 y 151.

70 Ibid., 129-135.

71 Ibid., 144.

72 Ibid., $135-143$ y 154

73 La crítica incluye a HART, Ross, Alchourrón y Bulygin, con especial énfasis en este último, cuya tesis, según FERRER, obligaría a forzar demasiado el sentido y fuerza de las normas de competencia para decir 
dad es parte de la norma de competencia para afirmar, en cambio, que la validez de una norma es una calificación externa al sistema que depende de lo previsto por el criterio de identificación del mismo que, a su vez, se remite a las normas de competencia y a las normas que condicionan su actualización ${ }^{74}$. Los sistemas jurídicos están integrados, según FERRER, por tres elementos: normas, definiciones y reglas constitutivas, aunque se podría sostener una clasificación con solo dos elementos: normas y reglas constitutivas porque, como prácticamente todas las definiciones legales son estipulativas, ellas serían una sub-categoría de las reglas constitutivas ${ }^{75}$.

Este panorama conceptual lo conduce a concluir que es posible distinguir tres tipos de normas acerca de la competencia: i) normas de competencia; ii) reglas que condicionan la actualización de la competencia, y iii) normas de conducta acerca del ejercicio de la competencia. Paralelamente, podrían distinguirse tres motivos de irregularidad de los actos jurídicos: i) haber sido realizados por un sujeto incompetente; ii) no haber seguido las reglas que indican las condiciones de actualización de la competencia, y (iii) ser un acto prohibido al menos para el sujeto que lo realizó. Los dos primeros tipos de irregularidad producen la invalidez del acto, mientras el tercero puede implicar que el sujeto deba ser sancionado ${ }^{76}$.

\subsection{Crítica al concepto de competencia}

Para demostrar que la propuesta de FERRER no es adecuada para explicar las normas de competencia, argumentaré que su concepto de competencia y, por tanto, su concepto de normas de competencia es, por un lado, demasiado amplio y, por otro lado, demasiado restringido.

\subsubsection{Demasiado amplio}

FERRER cree que las normas de competencia constituyen la competencia para realizar actos jurídicos normativos en sentido estricto, pero también actos jurídicos que no crean ni derogan normas. La supuesta ventaja de esta definición más amplia de competencia es que podría funcionar en ciertas situaciones en las que, conforme a las intuiciones básicas de los juristas, corresponde poder afirmar la competencia de los sujetos ${ }^{77}$. Pero esta definición implica una extensión del campo de aplicación del concepto de validez que no parece adecuarse a las mismas intuiciones. Un acto jurídico como conducir un automóvil realizado por un sujeto «competente» podría ser válido si cumple con las condiciones formales de actualización de la «competencia» ${ }^{78}$.

que cada una es una definición parcial del órgano competente, de la forma en que se pueden emitir normas válidas p del propio concepto de norma válida, ibid., 101-107 y 152.

74 Ibid., 137 y $155-156$.

75 La extensión de las reglas constitutivas no se agotaría en las normas de competencia debiendo también incluirse, por ejemplo, las normas derogatorias, ibid., 152 y nota 277 de ese trabajo.

76 Ibid., 157.

77 Ibid., 144.

78 Excluyo la condición sustantiva de actualización de la competencia porque, según FERRER, ella solo se aplica a la competencia para emitir normas, ibid., 138. Pero no veo inconveniente en que, desde la óptica de 
El argumento de FERRER es que la validez no solamente se predica correctamente de los actos que integran la actividad de producción y eliminación de normas válidas sino también de los que integran la actividad de aplicación de las normas válidas ${ }^{79}$. Pero este argumento pasa por alto que todos los actos que aplican normas válidas producen o integran la producción de normas válidas porque los actos jurídicos que no producen normas válidas no aplican ni integran la aplicación de normas validas; simplemente las acatan ${ }^{80}$.

La firma de las sentencias por el secretario y la sanción y promulgación de las leyes por el rey son efectivamente actos que integran la aplicación de normas válidas precisamente porque forman parte de un conjunto de actos que se dirigen a la producción de normas válidas. Pero no se puede decir lo mismo de la detención policial de individuos o la ejecución de una condena privativa de libertad que son actividades naturales o hechos brutos cuya existencia es independiente de toda regla, equivalentes a aparcar un coche o a conducir por el lado derecho de la calzada ${ }^{81}$. Su ejecución, aunque puede ser calificada por el derecho, no produce ni aplica normas jurídicas.

Es cierto que todos los actos jurídicos presuponen, como afirma FERRER, la realización de acciones naturales por parte de los sujetos ${ }^{82}$, pero allí no reside la posibilidad de diferenciar los actos naturales o físicos (como entregar dinero, conducir un automóvil, detener o poner en prisión a individuos) que pueden tener significado jurídico ${ }^{83}$ o ser interpretables en términos institucionales ${ }^{84}$ en cuanto son supuestos de hecho de normas que puramente disciplinan sus naturales efectos ${ }^{85}$ de las actos que, además, son normativos en el sentido que producen, modifican o derogan normas jurídicas válidas y, en consecuencia, aplican normas jurídicas válidas. Si la diferencia existe (como FERRER admite cuando advierte que su definición de competencia es más amplia que lo habitual), no parece posible dejar de notar que ella tiende a desdibujarse si el concepto de competencia se amplía en el sentido propuesto.

La importancia de esta diferencia dice relación con la muy diversa función que, en los discursos jurídicos, cumplen las nociones de licitud e ilicitud, por un lado, y las de validez e invalidez, por el otro. Los actos como la detención policial de individuos o la ejecución de una condena privativa de libertad pueden ser lícitos, si de acuerdo con el derecho son obligatorios o están permitidos y pueden ser ilícitos, generalmente sancionables, si de acuerdo con el derecho, se encuentran prohibidos o han sido ejecutados con infracción de las normas autorizantes ${ }^{86}$. Pero no tiene sentido afirmar que

\footnotetext{
este autor, el ejercicio de la competencia para realizar actos jurídicos no normativos pudiera estar sustantivamente limitado por normas superiores.

79 Ibid., 155. Al hacerlo apunta en la misma dirección de AGUILÓ, 1990: 280, y HART, 1982: 194 y ss.

80 Por esta razón se considera que solamente la producción y la aplicación del derecho son funciones jurídicas en un sentido más estricto y específico, KELSEN, 1991 (1960): 246.

81 Vid. Ross, 2000 (1968): 68, y SEARLE, 1997 (1995): 45.

82 FERRER, 2000: 145.

83 La acción de matar a otro puede tener el significado jurídico de «homicidio» e incluso el significado jurídico de la ejecución de una «pena de muerte», pero «matar a otro» sigue siendo una acción que puede ser realizada, descrita y comprendida sin referencia a las normas que la califican como homicidio o como pena de muerte, KELSEN, 1991 (1960): 15-16.

84 GONZÁLEZ LAGIER, 1995: 259-264.

85 FERRAJOLI, 2011 (2007): 464-465.

86 «Sancionables» por el tradicional vínculo que existe entre el concepto de ilicitud (entendido como violación de una obligación) y el concepto de sanción, KELSEN, 1991 (1960): 54, 126 y 130. «Generalmente san-
} 
son válidos o inválidos como los actos normativos en sentido estricto. El juez aplica una norma cuando dicta la que ordena la ejecución de una sentencia condenatoria, pero el funcionario que ejecuta la sentencia solamente acata la norma que le impone esa obligación ${ }^{87}$.

Un acto válido de producción de normas puede ser lícito si, siendo obligatorio, es realizado, y un acto inválido de producción de normas puede ser ilícito si, estando prohibido, es realizado. Incluso es posible, como FERRER admite, que un acto de producción de normas sea válido y prohibido (ilícito) ${ }^{88}$, como también sería posible que fuera obligatorio (lícito) e inválido. Pero un acto que no produce, modifica o deroga normas, como la ejecución una condena privativa de libertad, puede ser solamente lícito o ilícito. No puede ser válido o inválido.

Aunque de acuerdo con algunas intuiciones pueda parecer plausible afirmar que los funcionarios de las prisiones son competentes para ejecutar estas condenas, la consecuencia que se sigue es implausible, salvo que estemos dispuestos a aceptar que los juicios de validez e invalidez no están reservados para las normas y los actos que las producen aplicando otras normas y, por consiguiente, a aceptar que en el derecho no hay espacio para los juicios de mera licitud e ilicitud.

\subsubsection{Demasiado restringido}

Si la noción de validez está siempre conectada con la producción de normas, la validez y la invalidez se predican correctamente de los actos (legislativos, administrativos o judiciales) que producen normas y de las normas producidas por ellos.

Aunque en sentido estricto las condiciones formales de validez se refieren a los actos de producción de normas y las condiciones sustantivas de validez a las normas o disposiciones interpretadas ${ }^{89}$, no parece haber inconveniente en hablar siempre de validez (formal y sustantiva) de las normas que son el resultado de los actos que las producen.

Se puede convenir que las condiciones formales de la validez de una norma son tres: i) producción por el órgano competente; ii) observancia del procedimiento establecido para su producción, y iii) referencia de la norma a determinado ámbito material de regulación y no a otros. La validez sustantiva es, en cambio, una sola: el contenido de la norma no puede ser contradictorio con lo establecido en una norma superior ${ }^{90}$.

Usando un esquema parecido, FERRER descarta que las condiciones necesarias y suficientes de la validez de una norma sean definitorias de la competencia del sujeto que la ha creado. El concepto de competencia solamente incluye los aspectos personal

cionables» porque hay quienes afirman que también son ilícitos los actos puramente naturales que el derecho ha prohibido sin establecer una sanción, FERRAJOLI, 2011 (2007): 475-476.

87 KELSEN, 1991 (1960): 129-130.

${ }^{88}$ El ejemplo es tomado de HART y SPAAK y se refiere a la validez de la venta de cosas robadas, FERRER, 2000: 136.

${ }^{89} \mathrm{La}$ validez y la invalidez no pueden afirmarse, salvo de manera impropia, de disposiciones o formulaciones normativas no interpretadas ni de documentos normativos, sino exclusivamente de actos de producción (validez formal) y de normas o disposiciones interpretadas (validez sustantiva), ORUNESU, RODRíGUEZ y SUCAR, 2001: $23-24$.

90 Prieto Sanchís, 2009: 76-78. 
y material de la validez quedando excluidos (como «condiciones de actualización de la competencia»): i) el aspecto formal referido al procedimiento para producir normas, y ii) el aspecto sustantivo: el contenido de la norma creada no puede ser contradictorio con normas superiores.

Las disposiciones que regulan el procedimiento tienen, según FERRER, una cierta independencia de las normas de competencia. La razón más importante es que, si la competencia es la capacidad de producir ciertos resultados institucionales de acuerdo a las previsiones del sistema normativo, resulta irrelevante, a los efectos de determinarla, cuál sea el procedimiento que la autoridad competente debe seguir para producir el resultado (actualizar su competencia). Lo único necesario es que el sistema le ofrezca algún modo para producirlo. Así, si cambian las normas procesales, no cambian los órganos a los que se atribuye competencia ni la competencia sino únicamente las condiciones en que la competencia se puede actualizar ${ }^{91}$.

La constatación de que las reglas del procedimiento inciden en la competencia y en la validez de los actos o normas no autorizaría a concluir que las reglas procesales son definitorias de la propia competencia y hasta del órgano. Además, no todas las reglas procesales establecen condiciones de actualización de la competencia porque algunas imponen meras obligaciones cuyo incumplimiento no incide en la validez de los actos o normas dictadas ${ }^{92}$.

$\mathrm{El}$ argumento de FERRER no parece suficiente para derrotar la intuición (presente en Ross, HART, AlchourRón y Bulygin) de que la atribución de una competencia a un sujeto está condicionada al seguimiento de determinado procedimiento ${ }^{93}$. Como sugiere SEARLE, los pasos procedimentales para crear derechos y obligaciones son funciones de estatus o estatus deónticos condicionales ${ }^{94}$. Eso significa que cuando forman parte de un conjunto de actos que se dirigen a la producción de normas, se puede afirmar la competencia del sujeto que los realiza, como en el caso del secretario o del rey.

La importancia de la diferencia entre conferir una competencia y establecer las condiciones de su ejercicio no debe exagerarse hasta el punto de excluir las reglas procedimentales de la definición de competencia. Sobre todo, si para ello hay razones semejantes a las esgrimidas en favor de la conexión de los aspectos personal y material de la competencia. Basta recordar que reglas tan relevantes como las que establecen el quórum para aprobar normas son procedimentales. Si un órgano competente no las observa, los juristas estarían de acuerdo en que actuó fuera de su competencia que es igual a decir que era incompetente para hacer lo que hizo.

El concepto de competencia de FERRER es también demasiado restringido porque del mismo se excluyen los límites sustantivos de la validez de las normas.

Su primer argumento afirma que, si se concibe el principio lex superior como limitador de la competencia, un órgano sería únicamente competente para emitir normas

91 FERRER, 2000: 138 y 145.

92 Ibid., 138.

93 Incluso se sostiene que el no seguimiento de todas o algunas de las reglas de procedimiento, podría producir, antes que la invalidez de las normas creadas, la consecuencia más grave de inexistencia jurídica; GUASTINI, 1999 (1996): 320, 331-332, y 2001b: 60.

94 SEARLE, 1997 (1995): 111-115 y 121. 
que no fueran contrarias a lo dispuesto por normas superiores. Su consideración como condición de actualización de la competencia tendría, en cambio, la ventaja de ofrecer un rendimiento explicativo superior al de autores como HART, ROSS, o ALCHOURRÓN y BULYGIN porque permitiría dar cuenta de instituciones como la presunción de constitucionalidad de las leyes, la presunción de legalidad de los actos administrativos o el valor de cosa juzgada en las sentencias ${ }^{95}$.

Este argumento no es convincente porque la distinción entre validez y existencia ${ }^{96}$ permite dar perfecta cuenta de las instituciones mencionadas. Como FERRER cree, en cambio, que la validez es una calificación externa al sistema, a su juicio, el principio lex superior impide que la nueva norma se incorpore al sistema si ella no es válida ${ }^{97}$.

El segundo argumento consiste en que la exclusión del principio lex superior de la definición de la competencia tendría la ventaja de otorgar cierta estabilidad a la competencia que se atribuye a cada sujeto. Dicha competencia podría ser afectada solo por reglas constitutivas (de competencia o disposiciones derogatorias), mientras las reglas regulativas, sean acerca del ejercicio de la competencia o no, afectarían únicamente a las condiciones de actualización de la competencia ${ }^{98}$.

Este argumento incurre en la falacia de asumir implícitamente lo que pretende demostrar. FERRER asume, sin dar razones, que los límites sustantivos de la validez de las normas están establecidos en reglas regulativas, cuando esta es una conclusión que únicamente puede obtenerse a partir de la previa demostración de que tales límites no forman parte de la competencia constituida por reglas constitutivas. Por otra parte, si las normas superiores que establecen estos límites son regulativas tendría sentido pensar que, en lugar de normas que condicionan la actualización de la competencia, son normas de conducta acerca del ejercicio de la competencia cuya inobservancia implica una sanción. Pero FERRER está más bien asumiendo, nuevamente sin dar razones, que la invalidez es una consecuencia que puede seguirse de la inobservancia de normas regulativas ${ }^{99}$. El problema se origina principalmente porque nunca aclara qué entiende por reglas regulativas.

A falta de razones para excluir los límites sustantivos de la validez del concepto de competencia, hay una buena razón para defender la tesis opuesta. Si la validez formal y la validez sustantiva hacen referencia a cuestiones tan diferentes ${ }^{100}$, la común afirmación de validez jurídica en uno y otro caso no parece encontrar una mejor explicación que el hecho de que ella tiene un único y mismo sentido en el concepto de competencia cuya configuración está condicionada al cumplimiento de requisitos formales y sustantivos.

La circunstancia de que FERRER no lo advierta se deja explicar porque su definición de competencia acentúa la idea de que las normas de competencia amplían las

95 FERRER, 2000: 140.

96 GUASTINI, 2004: 254.

97 FERRER, 2000: 137-138.

98 Ibid., 138-139.

99 De hecho, FERRER afirma que una ley que vulnera lo establecido por una norma constitucional es inválida, ibid., 138-140.

${ }^{100}$ La primera solo puede afirmarse de los actos de producción de normas. La segunda solamente puede afirmarse del significado de las disposiciones normativas. 
posibilidades de actuación de los sujetos, obviando que del carácter institucional de la competencia también se extrae que las normas de competencia limitan sus posibilidades de actuación. El aspecto material de la competencia es un límite de la competencia personal porque vincula los diferentes tipos de normas a un ámbito material de regulación ${ }^{101}$. Alude a las cosas para las cuales se otorga competencia sin las cuales esta sería inconcebible seriamente ${ }^{102}$. Tanto es así que los vicios de incompetencia material pueden considerarse determinantes de un tipo invalidez o inconstitucionalidad formal ${ }^{103}$. Si este aspecto forma parte de la competencia, no parece haber razones suficientes para no decir lo mismo de los límites sustantivos de la validez y de las reglas procesales.

FERRER no ofrece buenas razones para concluir que las normas procedimentales y sustantivas cuya inobservancia determina la invalidez de los actos realizados por sujetos competentes no son normas de competencia sino normas que condicionan su actualización. Pero el problema más grave es que no aclara qué tipo de normas son. Esto permite discutir la consistencia de sus tesis sobre las reglas constitutivas y la validez jurídica.

Entre las razones de menor importancia que justificarían la independencia de las reglas de procedimiento respecto de las normas de competencia, FERRER menciona su heterogeneidad y las distintas consecuencias que se atribuirían al no seguimiento de cada uno de los tipos que existen pudiéndose al menos postular la existencia de reglas procesales constitutivas y reglas procesales que establecen obligaciones ${ }^{104}$. Si entiendo bien, estas últimas no podrían ser normas que condicionan la actualización de la competencia sino normas de conducta acerca del ejercicio de la competencia que, en consecuencia, no incidirían en la validez. Por su parte, las reglas procesales constitutivas condicionarían la actualización de la competencia, pero FERRER no aclara en qué sentido serían constitutivas. Esto es importante porque si no constituyen la competencia del sujeto para producir actos válidos, habría que admitir que son definiciones parciales de validez internas al sistema, lo que contradice los conceptos de regla constitutiva y validez jurídica defendidos por FERRER. Decir que ciertas reglas procesales condicionan la actualización de la competencia no es diferente a decir que, para que el ejercicio de la competencia sea válido, es necesario seguir cierto procedimiento. ¿Acaso esto no es una definición parcial e interna de validez?

Respecto de las normas superiores contrarias a la que se pretende dictar, FERRER tampoco es claro. Su argumento para considerar al principio lex superior como condición de actualización de la competencia asume, como hemos visto, que tales normas superiores son reglas regulativas y que de su inobservancia puede seguirse la invalidez. Como no ofrece razones que justifiquen estas asunciones pues no aclara qué entiende por reglas regulativas, hay dos opciones que parecen más plausibles para explicar estas normas superiores: i) son normas de conducta acerca del ejercicio de la competencia, en cuyo caso no inciden en la validez, y ii) son definiciones parciales e internas de

101 PRIETO SANCHÍs, 2009: 77.

102 CARRIÓ, 1994: 254.

103 Vid. PRIETO SANCHís, 2009: 77, y EzQUiaga, 2001: 68.

104 La otra razón sería que la normal complejidad de los procedimientos requeriría de un buen número de disposiciones para identificarlos paso por paso, FERRER, 2000: 126 y 152 y nota 224 de ese trabajo. 
validez, lo que contradice los conceptos de regla constitutiva y de validez defendidos por FERRER.

\subsection{Para concluir esta sección}

Aunque FERRER consigue eludir la discusión sobre cuál es el criterio correcto para distinguir las reglas constitutivas de las regulativas afirmando que las normas de competencia solamente constituyen la competencia de un sujeto para realizar actos jurídicos válidos en determinada materia, su tesis presenta dos problemas.

El primer problema es que, al asumir que la competencia no se constituye únicamente para realizar actos jurídicos normativos en sentido estricto sino también actos jurídicos que no producen, modifican ni derogan normas, se amplía inapropiadamente el campo de aplicación de los conceptos de validez e invalidez.

La supuesta ventaja de esta definición más amplia de competencia es que podría funcionar en algunas situaciones en que, conforme a las intuiciones básicas de los juristas, corresponde poder decir que los sujetos son competentes y la razón que justificaría estas intuiciones es que la validez no solo se predica correctamente de actos que integran la producción de normas válidas sino también de los que integran la aplicación de normas válidas. Pero FERRER se equivoca al desconocer que todos los actos jurídicos que aplican normas válidas (como la firma de las sentencias por el secretario y la sanción y promulgación de leyes por el rey) también producen normas válidas porque los actos que no las producen (como la detención policial de individuos o la ejecución de una sentencia condenatoria) tampoco aplican normas validas; simplemente las acatan. Como consecuencia, no advierte que los actos jurídicos no normativos solamente pueden ser lícitos o ilícitos, pero nunca válidos o inválidos.

El segundo problema de la tesis de FERRER es que obliga a considerar que las normas procedimentales y sustantivas cuya inobservancia determina la invalidez de los actos realizados por sujetos competentes no son normas de competencia sino normas que condicionan su actualización. La consecuencia que de ello se sigue es que la competencia se considera un requisito necesario, pero no suficiente de la validez que es una definición externa al sistema. La estrategia de FERRER fracasa porque no consigue explicar qué tipo de normas son las que condicionan la actualización de la competencia. Esta falta de claridad permite considerar que ellas pueden ser normas de conducta acerca de la competencia que, en consecuencia, no inciden en la validez o reglas constitutivas en un sentido que contradice las tesis de FERRER sobre las reglas constitutivas y la validez jurídica.

\section{BASES PARA UNA EXPLICACIÓN DE LAS NORMAS DE COMPETENCIA PRESCINDIENDO DE LA NOCIÓN DE REGLA CONSTITUTIVA}

Las razones por las cuales los esfuerzos de explicar las normas de competencia en función de la noción de regla constitutiva fallan sugieren que es necesario, o al menos conveniente, abandonar esta estrategia. Pero el objetivo de mostrar que, para ofrecer 
una adecuada explicación de estas normas, no es necesario ni conveniente considerarlas una especie de las reglas constitutivas no puede cumplirse plenamente sin mostrar que es posible una estrategia diferente.

En lo que sigue, expondré las bases de lo que, en mi opinión, podría ser una mejor explicación de las normas de competencia prescindiendo de la noción de regla constitutiva.

\subsection{Distinguiendo tipos de normas}

Dejando de lado la discusión sobre la distinción entre reglas regulativas y constitutivas, me parece que el criterio correcto para distinguir las normas regulativas de las normas de competencia es el modo en que ellas se relacionan con la actividad o las acciones a que se refieren y, por consiguiente, las diferentes consecuencias que se siguen de su observancia e inobservancia ${ }^{105}$.

Aunque no todas las normas regulativas y ni siquiera todas las que obligan imponen sanciones, el clásico vínculo entre los conceptos de obligación y sanción ${ }^{106}$, nos da una pista sobre la muy diversa función que, en los órdenes jurídicos, cumplen las normas regulativas y las normas de competencia. Como afirma BOBBIO, las normas secundarias sobre la sanción se dirigen a la conservación del sistema porque impiden la disolución de las normas de primer grado (que guían o controlan el comportamiento) a través de una continua inobservancia. Las normas sobre la producción normativa se dirigen, en cambio, a la transformación del sistema porque predisponen los mecanismos para la modificación consciente y tempestiva de las normas de primer grado ${ }^{107}$.

Como no siempre hay normas de segundo grado que impidan la disolución de las de primer grado, las normas regulativas pueden definirse como aquellas que, en un sistema jurídico, califican la realización o abstención de determinadas acciones o la consecución o no consecución de determinados fines ${ }^{108}$, como consecuencia de lo cual de su respectiva observancia e inobservancia no se sigue nunca la validez e invalidez. Por su parte, las normas de competencia pueden definirse como aquellas que, en un sistema jurídico, definen las competencias o potestades para producir, modificar o derogar normas jurídicas válidas o participar en su producción, modificación o derogación, como consecuencia de lo cual de su observancia e inobservancia se sigue siempre y respectivamente la validez y la invalidez ${ }^{109}$.

105 Hay una captación de una regla que se manifiesta, de caso en caso de aplicación, en lo que llamamos «seguir la regla» y en lo que llamamos «contravenirla», WITTGENSTEIN, 2008 (1953): parágrafo 201.

106 Vid., por ejemplo, KELSEN 1991 (1960): 129-131.

107 BOBBIO, 1990: 317-318. La distinción entre normas primarias que imponen obligaciones y derechos y las normas secundarias que estipulan una sanción para el caso de incumplimiento de las primeras se encuentra también en VON WRIGHT, 2010 (1983): 22.

108 Como al decir «califican» quiero significar «ordenan o permiten» esta parte de mi definición coincide con la caracterización que VON WRIGHT hace de las prescripciones o regulaciones, salvo porque aquí se considera que el contenido de las normas no está circunscrito únicamente a acciones y actividades, pues la autoridad normativa puede prescribir la obtención o la abstención de la obtención de fines, VON WRIGHT, 1970 (1963): 26-27, 87-107. 113.

109 He trazado esta distinción en términos similares aunque no idénticos en ARRIAGADA, 2015: 110, 112 - 


\subsection{Distinguiendo tipos de actos}

Como todos los actos humanos son naturales, físicos o brutos, el criterio para distinguir tipos de actos es si su realización y las consecuencias que de su realización se siguen han sido o no definidos por normas de competencia ${ }^{110}$ :

i) Los actos físicos que no son normativos pueden ser realizados, descritos y comprendidos sin referencia a norma alguna, aunque pueden ser calificados por normas jurídicas regulativas.

ii) Los actos son, además de físicos, normativos cuando su realización y las consecuencias que de ello se siguen han sido definidos por normas de competencia, de suerte que solamente pueden ser realizados, descritos y comprendidos de acuerdo con ellas ${ }^{111}$.

Nada de esto impide que, una vez definidos, los actos normativos sean calificados por normas regulativas ${ }^{112}$. Por eso conviene hablar de normas de competencia y normas acerca de la competencia.

\subsection{Normas de competencia y normas acerca de la competencia}

Mi definición de normas de competencia implica las siguientes subtesis ${ }^{113}$ :

i) Una norma es jurídicamente «válida» cuando ha sido producida de conformidad con las normas (de competencia) que, en un sistema jurídico, definen las potestades o competencias para producirla ${ }^{114}$.

ii) La «competencia» es la posibilidad que ciertas normas de un sistema jurídico atribuyen a un sujeto de producir, modificar o derogar en las condiciones definidas por esas mismas normas, normas jurídicas válidas. Esta posibilidad incluye la de participar en dichas producción, modificación o derogación ${ }^{115}$.

110 Una distinción similar es la de «actos informales» y «actos formales» propuesta en FERRAJOLI, 2011 (2007): 464-465. El análisis que mejor da cuenta de la distinción entre tipos de acciones dependiendo de si han sido definidas o no por normas de competencia, así como de la distinción entre estas normas y las regulativas es el de HOHFELD sobre las posiciones jurídicas subjetivas, HOHFELD, 2010 (1913) y 2010 (1917). Me he referido al uso implícito que hace HOHFELD de estas distinciones en ARRIAGADA, 2016: 154-157. Una aplicación de las mismas distinciones al análisis de los derechos fundamentales puede verse en ARRIAGADA, 2015.

111 Por ejemplo, los actos que el ordenamiento jurídico prevé para el otorgamiento de un testamento o la dictación de una ley o una sentencia judicial.

112 La facultad, potestad o capacidad de producir derecho conferida a un individuo puede ser simultáneamente obligatoria, KELSEN, 1991 (1960): 132. Las potestades pueden ser reforzadas mediante deberes, HART, 2009 (1961): 37 y 120. La permisión es algo puede darse tanto respecto de actos ordinarios como respecto de actos jurídicos, Bulygin, 1991 (1988): 489. Una cosa es conferir un poder (normativo) y otra es regular el ejercicio de ese poder, ATIENZA y RUIZ MANERO, 2004: 84.

113 ARRIAGADA, 2015: 112-113.

114 La validez es un juicio según un sistema de normas, un juicio jurídico que aplica normas jurídicas a determinados hechos, Ross, 1991a (1961): 23. La validez de una norma hace referencia a su creación regular o sin vicios y depende de la conformidad con normas de jerarquía superior, ORUNESU, 2012: 119-120, y GUASTINI, 2001b: 60. Es lo que KELSEN denomina el fundamento de validez, KELSEN, 1991 (1960): 201-208.

115 La competencia no solo comprende el poder jurídico de los órganos públicos para producir normas generales o individuales, sino también la capacidad, que el orden jurídico confiere a los individuos, de participar en la producción de normas generales o individuales, KELSEN, 1991 (1960): 159-161 y 151-157. 
En principio es razonable considerar que las normas de competencia son básicamente de dos tipos. Las del primer tipo podrían denominarse «normas que confieren competencia» porque atribuyen a determinados sujetos la competencia para producir normas jurídicas válidas en determinado ámbito material de regulación. Las del segundo tipo podrían llamarse «meta-normas de competencia» pues definen las condiciones para el ejercicio de las competencias conferidas por las normas del primer tipo. Ellas incluyen tanto las normas que definen el procedimiento para su ejercicio como las que definen los límites de contenido que las normas producidas no pueden sobrepasar.

Los tipos y subtipos descritos pueden expresarse o estar implícitos en una o más disposiciones o fragmentos de disposiciones normativas. La clasificación propuesta no supone aceptar la idea de que una norma de competencia completa debe contener todos los aspectos de la competencia ${ }^{116}$ porque las normas de competencia podrían determinar exclusivamente el órgano o individuo que producirá las nuevas normas ${ }^{117}$.

Llegados a este punto, puede decirse que las normas de competencia son definiciones de validez jurídica internas al sistema y que estas definiciones son formales o sustantivas. Pero esta subdivisión y, por consiguiente, la subdivisión propuesta dentro de las normas de competencia del segundo tipo se justifica únicamente por razones didácticas.

Como KELSEN ha puesto de relieve mediante la distinción entre la «constitución en sentido formal» y la «constitución en sentido material» a la luz del objetivo de la jurisdicción constitucional, el aspecto procedimental y los límites sustantivos de la competencia (y de la validez) representan dos formas de mirar una única y misma cosa.

La constitución en sentido formal expresa una decisión de autolimitación en cuya virtud las medidas que afectan una determinada esfera de intereses solo son posibles en virtud de un acuerdo entre mayoría y minoría. Es el documento que contiene disposiciones según las cuales las normas contenidas en él no pueden ser derogadas o modificadas como simples leyes sino solo bajo condiciones más difíciles. Estas disposiciones configuran la forma de la constitución y sirven para estabilizar las normas de la constitución en sentido material que, en cambio, constituyen el fundamento y estrato superior jurídico-positivo de todo orden jurídico estatal al regular la producción de normas jurídicas generales ${ }^{118}$. Dicho de otro modo: i) las normas constitucionales no puedan ser modificadas del mismo modo que las demás normas, y ii) la conformidad con las normas constitucionales es una condición de validez de cualquier norma de suerte que una norma que pretenda modificar la constitución es inválida ${ }^{119}$.

Que la distinción es únicamente una cuestión de sentido se hace evidente cuando KELSEN explica que la jurisdicción constitucional en relación con las normas de inferior jerarquía solamente es posible cuando las normas materialmente constitucionales son también formalmente constitucionales. Esto significa que la decisión de anular una norma inconstitucional por razones de «contenido» no se fundamenta en la norma misma

116 En contra, AtienZa y Ruiz MANero, 2004: 85-86.

117 Así lo cree KELSEN al referirse a la norma superior que determina la producción de una norma inferior o de normas facultativas que son no independientes porque solamente determinan una de las condiciones a las cuales una norma independiente enlaza el acto coactivo, KELSEN, 1991 (1960): 68 y 245.

118 KeLSEN, 2009a (1929): 140-142, y 1991 (1960): 232-233.

119 GuASTINI, 2001a: 188-189 y 193. 
sino en el «hecho» de no haber sido producida por el órgano y conforme al procedimiento de reforma constitucional. La jurisdicción constitucional consiste simplemente en que una norma debe ser anulada en su validez general (para todos los casos) o particular (para un caso concreto) porque el hecho concreto de su producción se encuentra en contradicción con la norma que regula ese hecho y que por ello es una norma superior ${ }^{120}$.

Cuando las cortes constitucionales controlan la constitucionalidad de normas generales emanadas de la legislación (en abstracto o en concreto) ${ }^{121}$ o la constitucionalidad de normas particulares producidas por órganos administrativos ${ }^{122}$, solamente deben verificar que las normas que dispongan medidas que afectan a una esfera de intereses cuya regulación exige una reforma constitucional hayan sido producidas por el órgano y mediante el procedimiento para realizar esa reforma. Esto implica que la validez de una norma cuya producción ha sido, por razones sustantivas o de contenido, reservada a la competencia de determinado órgano y condicionada al seguimiento de cierto procedimiento, depende únicamente de que haya sido producida por ese órgano y conforme a ese procedimiento.

Si la validez y la competencia sustantiva se disuelven en la validez y la competencia formal, las normas de competencia son simplemente definiciones internas de validez jurídica. Por su parte, las normas que califican la realización de los actos normativos definidos por normas de competencia son normas regulativas acerca de la competencia.

\section{BIBLIOGRAFÍA CITADA}

Aguiló, J., 1990: «Sobre definiciones y normas», Doxa, 8: 273-282.

Alchourrón, C., y BuLYGin, E., 1991 (1981): «La concepción expresiva de las normas», en C. Alchourrón y E. Bulygin, Análisis lógico y derecho, Madrid: Centro de Estudios Políticos y Constitucionales, 121-153.

- 1991 (1983): «Definiciones y normas», en C. AlCHOURRÓn y E. BulYgin, Análisis lógico y derecho, Madrid: Centro de Estudios Políticos y Constitucionales, 439-463.

ARRIAGADA, M. B., 2015: «Las cortes constitucionales frente a los "derechos civiles y políticos". Una mirada desde la teoría analítica del derecho», Revista española de derecho constitucional, 105, septiembre-diciembre: $105-136$.

- 2016: «Conceptos de derecho subjetivo», Eunomía. Revista en cultura de la legalidad, 11, Universidad Carlos III de Madrid: 152-162.

Atienza, M., y Ruiz Manero, J., 2004: Las piezas del derecho, Barcelona: Ariel.

BobBio, N., 1990: Contribución a la teoría del derecho, Madrid: Debate (trad. de A. Ruiz Miguel).

BulYgin, E., 1991 (1976): «Sobre la regla de reconocimiento», en C. AlCHOURRón y E. BulYGIN, Análisis lógico y derecho, Madrid: Centro de Estudios Políticos y Constitucionales, $383-391$.

- 1991 (1988): «Sobre las normas de competencia», en C. AlCHOURRÓn y E. BulYGin, Análisis lógico y derecho, Madrid: Centro de Estudios Políticos y Constitucionales, 485-498.

120 KeLSEN, 2009b (1931): 311-314. Para una explicación de la dificultad que tendría obligar a un órgano legislativo colectivo a no dictar normas inconstitucionales, vid. KELSEN, 1991 (1960): 155-156 y 234.

121 Invalidación de una norma general con efectos generales (inconstitucionalidad) o limitados al caso concreto (inaplicabilidad), ibid., 313-314.

122 Actos del Gobierno, especialmente los decretos, KELSEN, 2009b (1931): 302. 
CARCATERRA, G., 1979: La forza costitutiva delle norme, Roma: Bulzoni.

- 2014: Le norme costitutive, Torino: Giappichelli.

CARRIÓ, G., 1994: Notas sobre derecho y lenguaje, Buenos Aires: Abeledo Perrot.

Conte, A. G., 1989: Filosofia del linguaggio normativo I, Studi 1965-1981, Torino: Giappichelli.

- 1995: Filosofia del Linguaggio Normativo II, Studi 1982-1994, Torino: Giappichelli.

- 2001: Filosofia del linguaggio normativo III, Studi 1995-2001, Torino: Giappichelli.

EzQuiaga, F. J., 2001: «Sobre inconstitucionalidad y derogación», Discusiones, 2: 65-78.

Ferrajoli, L., 2011 (2007): Principia iuris. Teoría del derecho y de la democracia, Madrid: Trota (trad. de P. Ibáñez, C. Bayón, M. Gascón, L. Prieto Sanchís y A. Ruiz Miguel).

FERRER, J., 2000: Las normas de competencia. Un aspecto de la dinámica jurídica, Madrid: Centro de Estudios Políticos y Constitucionales.

GonZÁlez LagIer, D., 1995: Acción y norma en G. H. Von Wright, Madrid: Centro de Estudios Políticos y Constitucionales.

- 2000: G. H. Von Wright y los Conceptos Básicos del Derecho, México D. F.: Fontamara.

GuAstini, R., 1984: «Teorías de las reglas constitutivas. Searle, Ross y Carcaterra», Revista de Ciencias Sociales, 25 (Alf Ross, Estudios en su homenaje): 297-315.

- 1999 (1996): Distinguiendo. Estudios de teoría y metateoría del derecho, Barcelona: Gedisa (trad. de J. FERRER).

- 2001a: Estudios de teoría constitucional, México D. F.: Fontamara.

— 2001b: «Cinco observaciones sobre validez y derogación», Discusiones, 2: 59-63.

— 2004: «Proyecto para la voz "ordenamiento jurídico" de un diccionario», Doxa, 27: 247-282 (trad. de M. Atienza y J. Ruiz MAnero).

— 2008 (2010): «Fundamentos de una teoría escéptica de la interpretación», en I. LIFANTE (ed.), Interpretación jurídica y teoría del derecho, Lima: Palestra (trad. de D. MORENO CRUZ), 147-172.

- 2014: Interpretar y argumentar, Madrid: Centro de Estudios Constitucionales (trad. de S. ÁLVAREZ).

- 2014 (2013): Otras distinciones, Bogotá: Universidad Externado de Colombia (trad. de D. DEL VeCChi, P. CABAllero y A. CALZETTA).

HART, H. L. A., 1962 (1953): «Definición y teoría en la ciencia juridical», en Derecho y moral. Contribuciones a su análisis, Buenos Aires: Depalma (trad. de G. CARRIÓ), 93-130.

- 1980: «El nuevo desafío al positivismo jurídico», Sistema, 36 (trad. de F. LAPORTA y J. R. PÁRAMO), 3-18.

- 1982: «Legal powers», en Essays on Bentham. Studies in Jurisprudence and Political Theory, New York: Oxford University Press, 194-219.

- 2009 (1961): El concepto de derecho, Buenos Aires: Abeledo Perrot (trad. de G. CARrió).

HOHFELD, W., 2010 (1913): «Some fundamental legal conceptions as applied in judicial reasoning», en W. WHEELER COOK (ed.), Fundamental legal conceptions as applied in judicial reasoning, New Heaven and London: Yale University Press, 23-64.

- 2010 (1917): «Fundamental legal conceptions as applied in judicial reasoning», en W. WHEELER COOK (ed.), Fundamental legal conceptions as applied in judicial reasoning, New Heaven and London: Yale University Press, 65-114.

Kelsen, H., 1991 (1960): Teoría pura del Derecho (2. ${ }^{a}$ ed.), México D. F.: Porrúa (trad. de R. VERNENGO).

- 2009a (1929): De la esencia y valor de la democracia, Oviedo: KRK Ediciones (trad. de J. L. REQUeJo). 
— 2009b (1931): «¿Quién debe ser el defensor de la Constitución?», en C. SCHMiTT y H. KELSEN, La polémica Schmitt/Kelsen sobre la justicia constitucional: El defensor de la Constitución versus ¿Quién debe ser el defensor de la Constitución?, Madrid: Tecnos (trad. de R. J. BRIE), 289-366.

Orunesu, C., 2012: Positivismo Jurídico y sistemas constitucionales, Madrid: Marcial Pons.

Orunesu, C.; Rodríguez, J., y Sucar, G., 2001: «Inconstitucionalidad y derogación», Discusiones, 2: 11-58.

Prieto Sanchís, L., 2009: Apuntes de Teoría del Derecho, Madrid: Trotta.

RAZ, J., 1991 (1975): Razón práctica y normas, Madrid: Centro de Estudios Constitucionales (trad. de J. RuIZ MANERO).

Ross, A., 1991a (1961): «El concepto de validez y el conflicto entre el positivismo jurídico y el derecho natural», en El concepto de validez y otros ensayos, México: Fontamara (trad. de G. CARRIÓ y O. PASCHERO), 7-29.

- 1991b (1961): «Sobre los conceptos de "Estado" y "Órganos del Estado" en Derecho Constitucional», en El concepto de validez y otros ensayos, México: Fontamara (trad. de E. VÁSQUEZ), 73-92.

- 1991c (1969): «Sobre la auto-referencia y un difícil problema de derecho constitucional», en El concepto de validez y otros ensayos, México: Fontarama (trad. de E. BulYGin y E. Garzón VALDÉs), 43-71.

- 1991d (1972): «Grandeza y decadencia de la doctrina de las expresiones realizativas», en El concepto de validez y otros ensayos, México: Fontarama (trad. de E. Bulygin y E. Garzón VALDÉs), 93-115.

- 2000 (1968): Lógica de las normas, Colmares: Granada (trad. de J. HiERro).

- 2005 (1958): Sobre el derecho y la justicia, Buenos Aires: Eudeba (trad. de G. CARRIÓ).

Roversi, C., 2014: «Conceptualizing institutions», Phenomenology and the Cognitive Sciences, 13, 1: 201-215.

RUiz MANERO, J., 2005: «Una tipología de las normas constitucionales», en J. AGUILÓ, M. ATIENZA y J. RuIZ MANERO, Fragmentos para una teoría de la constitución, Madrid: Iustel, 63-112.

SEARLE, J., 1964: «How to derive "ought" from "is”», The Philosophical Review, vol. 73, núm. 1, 43-58.

- 1997 (1995): La construcción de la realidad social, Barcelona: Paidos (trad. de A. DomènECH).

- 2007 (1969): Actos de habla. Ensayo de Filosofía del Lenguaje, Madrid: Cátedra (trad. de L. M. VALDÉs VilLanueva).

Schauer, F., 2004 (1991): Las reglas en juego, Madrid: Marcial Pons (trad. de C. Orunesu y J. RODRÍGUEZ).

Vilajosana, J., 2010: El derecho en acción. La dimensión social de las normas jurídicas, Madrid: Marcial Pons.

VON Wright, G., 1970 (1963): Norma y acción. Una investigación lógica, Madrid: Tecnos (trad. de P. García Ferrero).

- 1979 (1971): Explicación y comprensión, Madrid: Alianza.

- 2010 (1983): Normas, verdad y lógica, México D. F.: Fontarama (trad. de C. AlarCón CABRERA).

WiTTGENSTEIN, L., 2008 (1953): Investigaciones filosóficas, Barcelona: Crítica (trad. de A. GARCÍA SuÁreZ y U. MOULines). 